\section{Rediscovery of Ginalloa andamanica Kurz (Angiosperms: Viscaceae) - an endemic and threatened species from Little Andaman Island, India}

\author{
L. Rasingam ${ }^{1}$, P. Lakshminarashimhan ${ }^{2} \&$ \\ P.G. Diwakar ${ }^{3}$
}

${ }^{1}$ Botanical Survey of India, Andaman and Nicobar Circle, Port Blair 744102, India

${ }^{1}$ Present Address: Keystone Foundation, Kotagiri, The Nilgiris, Tamil Nadu 643217, India

${ }^{2}$ Botanical Survey of India, Central National Herbarium,

P.O. Botanic Garden, Howrah, Kolkata 711103, India

${ }^{3}$ Botanical Survey of India, Western Circle, Pune, Maharashtra 411001, India

Email: ${ }^{1}$ rasingam@gmail.com; ${ }^{2}$ lakshminarasimhanp@yahoo. co.in; ${ }^{3}$ pgdiwakar@ hotmail.com

The genus Ginalloa Korth. belonging to Viscaceae of Indo-Malesian region comprises of nine species (Mabberley 2008), of which two species, viz., G. andamanica Kurz and $G$. helferi Kurz are known to occur on Andaman Islands, India (Karthigeyan et al. 2009). The endangered semi-parasitic shrub Ginalloa andamanica, was described by Kurz in 1872 and has been considered endemic to the South Andaman Island. In the Flora of British India, J.D. Hooker (1886) included this species, without seeing the specimen, based on the Kurz's report. Later Balakrishnan \& Rao (1983) and Nayar \& Sastry (1990) treated it as rare and endangered in Andaman and Nicobar Islands. While revising the family Viscaceae

Date of publication (online): 26 August 2010

Date of publication (print): 26 August 2010

ISSN 0974-7907 (online) | 0974-7893 (print)

Editor: N.P. Balakrishnan

Manuscript details:

Ms \# 02419

Received 04 March 2010

Final revised received 19 July 2010

Finally accepted 23 July 2010

Citation: Rasingam, L., P. Lakshminarashimhan \& P.G. Diwakar (2010) Rediscovery of Ginalloa andamanica Kurz (Angiosperms: Viscaceae) an endemic and threatened species from Little Andaman Island, India. Journal of Threatened Taxa 2(9): 1158-1159.

Copyright: (c) L. Rasingam, P. Lakshminarashimhan \& P.G. Diwaka 2010. Creative Commons Attribution 3.0 Unported License. JoTT allows unrestricted use of this article in any medium for non-profit purposes, reproduction and distribution by providing adequate credit to the authors and the source of publication.

Acknowledgements: The authors thank Dr. M. Sanjappa, Director Botanical Survey of India, Kolkata for facilities and logistic support; ANFPDCL for permission. First author (LR) thanks Dr. D. Kannan, Thiyagarajar College, Madurai for encouragement.

\section{OPEN ACCESS | FREE DOWNLOAD (C) (i) (4)}

for India, Sanjai \& Balakrishnan (2006) could not either collect or see any specimen. Hooker (1886) and Barlow (1997) doubted the existence of this species. While surveying the Little Andaman Island, one of us (LR) collected a sample of this species from the broken branches of Artocarpus chama Buch.-Ham. in the inland evergreen forests. The distribution of the species is extremely rare and only a few individuals were noted on that tree and most of them were very healthy. The tree was found in association with Alstonia kurzii Hook.f., Dipterocarpus gracilis Blume, Dipterocarpus grandiflorus Blanco, Drimycarpus racemosus (Roxb.) Hook.f., Dysoxylum arborescens (Blume) Miq., Kopsia scortechinii King \& Gamble and Melicope glabra (Blume) T.G. Hartley. The Island was initially declared as tribal reserve in 1957 and later as a reserve forests in 1963. This species is rediscovered after a lapse of 136 years. Sanjai \& Balakrishnan (2006) reported the non-availability of specimens in the Indian herbaria and lack of information. Hence, a detailed description with line diagram is provided here.

\section{Ginalloa andamanica Kurz}

in J. Asiat. Soc. Bengal, Pt. II, Nat. Hist. 41(2): 309. 1872 \& Forest FI. Burma 2: 326. 1877; Hook. f., FI. Brit. India 5: 228. 1886; M.P. Nayar \& Sastry, Red Data Book Ind. PI. 3: 259. 1990; Sanjai \& N.P. Balakr. in Rheedea 16: 80. 2006. (Image 1; Fig.1).

Specimen examined: 15.v.2007, area between Krishna Nallah and Nanjappa Nagar, Little Andaman Island, Andaman and Nicobar Islands, India, coll. L. Rasingam, \#25930 (PBL - Herbarium of the Botanical Survey of India, Andaman \& Nicobar Regional Centre, Port Blair), preserved samples mutilated.

Aerial semi-parasitic shrub, ca. $80 \mathrm{~cm}$ high; branchlets dark black, terete, longitudinally wrinkled, with whitish, ellipsoid lenticels, glabrous; internodes up to $4 \mathrm{~cm}$ long. Normal leaves obovate to ovate-oblong or suborbicular, 2-6.5 x 1-4 cm, rounded at apex, base oblique, attenuate and contracted into the petioles, entire along margins, wavy when dry, thickly coriaceous, dark black, glabrous; nerves three, obscure above, visible beneath; petioles very short, up to $2 \mathrm{~mm}$ long or obsolete, glabrous. Rudimentary cataphyll-like leaves borne ca. $5 \mathrm{~mm}$ above the base of each branch, ca. $1 \mathrm{~mm}$ long, glabrous. Inflorescence axillary and terminal spike of decussate pairs of cymules, ca. $5 \mathrm{~cm}$ long; bracteoles entire to shortly fimbriate, densely clothed with stellate crystals. Male flowers very small, globose, ca. $2 \mathrm{~mm}$ long, petals three, ca. $1 \mathrm{~mm}$ long, glabrous. Female flowers cylindric. Fruits ellipsoid, slightly tuberculate, angled, ca. $7 \times 3 \mathrm{~mm}$, glabrous, crowned by short persistent calyx.

Flowering \& Fruiting: February-June. 


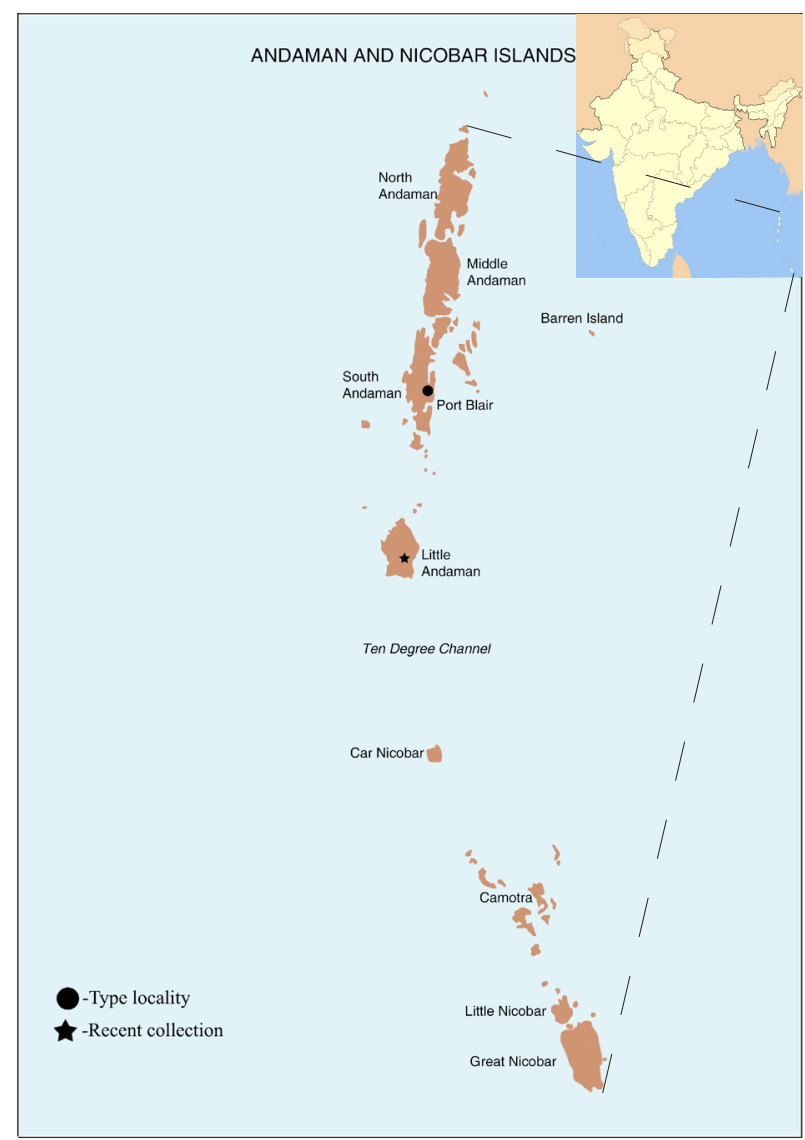

Image 1. Andaman and Nicobar Islands giving the distribution of Ginalloa andamanica Kurz

Distribution: South and Little Andaman Islands (Endemic)

Habitat: Branches of Artocarpus chama Buch.-Ham. Very rare in inland evergreen forests.

\section{REFERENCES}

Balakrishnan, N.P. \& M.K.V. Rao (1983). The dwindling plant species of Andaman \& Nicobar Islands, pp.186-201. In: Jain, S.K. \& R.R. Rao (eds.). An Assessment of Threatened Plants of India. Botanical Survey of India, Calcutta.

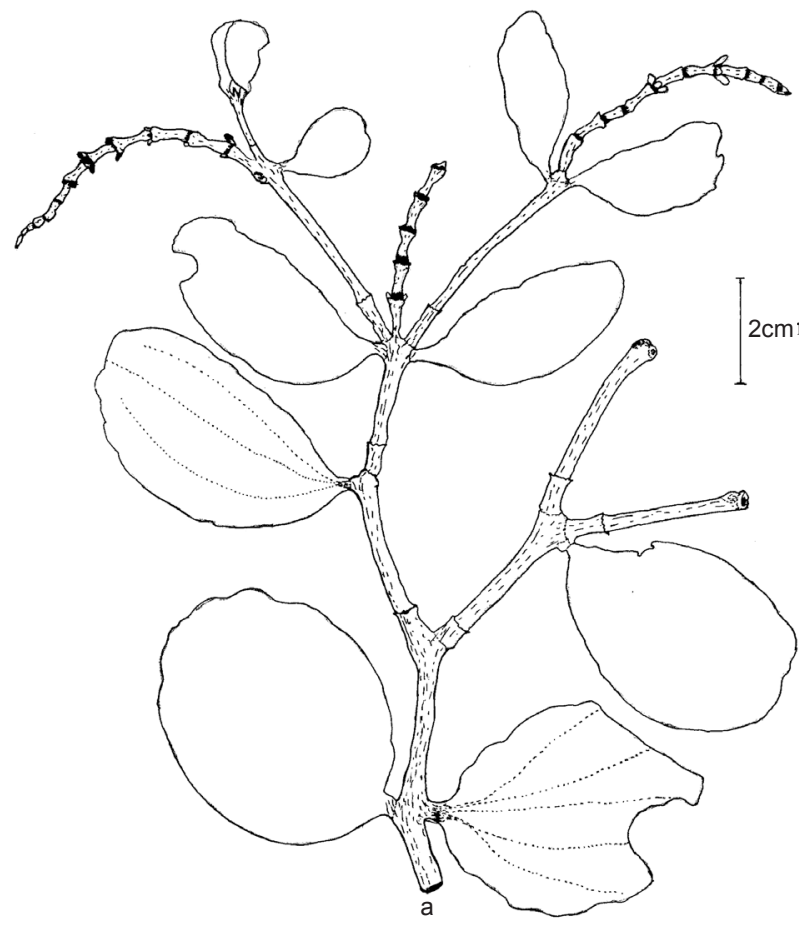

Figure 1. Ginalloa andamanica Kurz a - Habit

Barlow, B.A. (1997). Viscaceae, pp.403-442. In: Kalkman, C., D.W. Kirkup, H.P. Nooteboom, P.F. Stevens \& W.J.J.O. de Wilde (eds.). Flora Malesiana, Series 1, Spermatophytes 13

Hooker, J.D. (1886). Flora of British India - Vol. 5, pp.228. L. Reeve \& Co, London, 864+46index pp.

Karthigeyan, K., R. Sumathi, J. Jeyanthi \& P.G. Diwakar (2009). New records of plants to the flora of India from South Andaman Island. Indian Journal of Forestry 32(2): 301-303.

Mabberley, D.J. (2008). Mabberley's Plant-book: A Portable Dictionary of Plants: Utilizing Kubitzki's The Families and Genera of Vascular Plants (1990-) and Current Botanical Literature, Arranged According to The Principles of Molecular Systematics - Edition 3. Cambridge University Press, xviii+1021pp.

Nayar, M.P. \& A.R.K. Sastry (1990). Red Data Book of Indian Plants - Vol 3, pp.259. Botanical Survey of India, Calcutta, $271+7$ index pp.

Sanjai, V.N. \& N.P. Balakrishnan (2006). A revision of Indian Viscaceae. Rheedea 16: 80. 2006. 